\title{
Supplementation and therapeutic use of vitamin D in patients with multiple sclerosis: Consensus of the Scientific Department of Neuroimmunology of the Brazilian Academy of Neurology
}

\author{
Suplementação e uso terapêutico de vitamina $D$ nos pacientes com esclerose \\ múltipla: Consenso do Departamento Científico de Neuroimunologia da Academia \\ Brasileira de Neurologia \\ Doralina Guimarães Brum¹, Elizabeth Regina Comini-Frota², Claúdia Cristina F. Vasconcelos ${ }^{3}$, Elza Dias-Tosta 4
}

\begin{abstract}
Multiple sclerosis (MS) is an inflammatory, autoimmune, demyelinating, and degenerative central nervous system disease. Even though the etiology of MS has not yet been fully elucidated, there is evidence that genetic and environmental factors interact to cause the disease. Among the main environmental factors studied, those more likely associated with MS include certain viruses, smoking, and hypovitaminosis D. This review aimed to determine whether there is evidence to recommend the use of vitamin D as monotherapy or as adjunct therapy in patients with MS. We searched PUBMED, EMBASE, COCHRANNE, and LILACS databases for studies published until September $9^{\text {th }}, 2013$, using the keywords "multiple sclerosis", "vitamin D", and "clinical trial". There is no scientific evidence up to the production of this consensus for the use of vitamin D as monotherapy for MS in clinical practice.
\end{abstract}

Keywords: vitamin D, multiple sclerosis, experimental autoimmune encephalitis.

RESUMO

A esclerose múltipla (EM) é uma doença inflamatória, autoimune, desmielinizante e degenerativa do sistema nervoso central. Estudos epidemiológicos têm identificado associações de hipovitaminose D com doenças autoimunes. 0 principal objetivo desta revisão é responder se há evidências que indiquem o uso terapêutico de vitamina D em monoterapia para pacientes com EM. Por meio dos sites PUBMED, EMBASE, LILACS e Scielo foram realizadas buscas usando os descritores "vitamin D", e "multiple sclerosis" até 12/09/2013. Estudos clínicos randomizados, controlados e duplo-cegos foram selecionados para avaliar a resposta terapêutica da vitamina D na EM. Não foram encontradas evidências científicas que justifiquem o uso da vitamina D em monoterapia no tratamento da EM, na prática clínica.

Palavras-chave: Vitamina D, esclerose múltipla, encefalite autoimune experimental.

\footnotetext{
'Departamento de Neurologia, Psicologia e Psiquiatria, Faculdade de Medicina de Botucatu, Universidade Estadual Paulista, Botucatu SP, Brazil;

${ }^{2}$ Hospital das Clínicas, Universidade Federal de Minas Gerais, Belo Horizonte MG, Brazil;

${ }^{3}$ Universidade Federal do Rio de Janeiro, Rio de Janeiro RJ, Brazil;

${ }^{4}$ Hospital de Base do Distrito Federal, Brasília DF, Brazil.

Correspondence: Doralina G. Brum. Departamento de Neurologia, Psicologia e Psiquiatria da Faculdade de Medicina de Botucatu, Universidade Estadual Paulista - UNESP. Distrito de Rubião Júnior, s/n; 18618-970 Botucatu SP, Brasil. E-mail: dbrum@fmb.unesp.br

Conflict of interest: The Brazilian Academy of Neurology (ABN) is committed to produce clinical guidelines critically and independently. This guideline is part of ABN's continuing education activity. It is based on review of scientific and clinical knowledge. Its purpose is not to address the subject in its entirety. Treatment decision is shared between patient and physician and according to each situation.

Support: This guideline was developed with financial support from the Brazilian Academy of Neurology. None of the authors received honoraria for their participation.

The conflict of interest form for the issue specifically addressed in this article was signed by all authors.

List of contributors: Amilton Antunes Barreira, Antônio Pereira Gomes Neto, Cláudio Roberto Carneiro, Carlos Augusto de Albuquerque Damasceno, Daniel Lima Varela, Damácio Rámon Kaimen-Maciel, Denis Bernardi Bichuetti, Denise Sisterolli Diniz, Eber Castro Correa, Elizabeth Batista da Silva, Fabio Siquineli, Fernando Coronetti Gomes da Rocha, Felipe von Glehn Silva, Fernando Faria Andrade Figueira, Gutemberg Augusto Cruz dos Santos, Heloise Helena de Figueiredo Siqueira, Jefferson Becker, Leandro Cortoni Calia, José Mauricio Godoy Barreiros, Luiz Domingos Mendes Melges, Marcos Aurélio Moreira, Marcos Papais-Alvarenga, Maria Cecília Aragon de Vecino, Maria Cristina Brandão de Giacomo, Maria Fernanda Mendes, Maria Lúcia Brito Ferreira, Maria Lúcia Vellutini Pimentel, Monica Koncke Fiuza Parolin, Nívea de Macedo Oliveira Morales, Osvaldo J.M. do Nascimento, Paulo Pereira Christo, Regina Maria Papais Alvarenga, Renata Brandt de Souza, Renato Puppi Munhoz, Rogério de Rizo Morales, Sidney Gomes, Solange Maria das G. G. Camargo, Soniza Vieira Alvez-Leon, Suzana Costa Nunes Machado, Tarso Adoni, Thereza Cristina D`Avila Winckler, Thiago de Faria Junqueira, Yara Dadalti Fragoso, and Yuna de Ribeiro Araújo.

External collaborators: Alessandro Farias (researcher), Eduardo Antônio Donadi (immunologist), and Marcelo de Paula Corrêa (meteorologist).

Received 10 January 2014; Accepted 20 January 2014
} 
The therapeutic use of vitamin $\mathrm{D}$ for treating multiple sclerosis (MS) is a controversial issue that is of interest to physicians, researchers, and patients. The Scientific Department of Neuroimmunology (DCNI) of the Brazilian Academy of Neurology (ABN) organized a meeting on September 12, 2013, to discuss the basic aspects of vitamin D metabolism, results of in vitro and experimental studies on experimental autoimmune encephalomyelitis (EAE), and controlled clinical trials of vitamin D in MS. Neurologists and researchers participating in the meeting approved a guideline consensus to guide Brazilian neurologists in the care of patients with MS.

\section{VITAMIN D, MS, AND EAE}

Vitamin D is an important hormone for calcium homeostasis and bone metabolism ${ }^{1}$. Besides its action in bone tissue, vitamin D has a role in cell differentiation, cell growth inhibition, and immune system modulation ${ }^{2}$. The main source of vitamin D is ultraviolet-B radiation (95\%). However, no consensus has been reached on optimal serum vitamin D levels for human metabolic needs ${ }^{3,4}$. The association between vitamin D and autoimmune diseases and neoplasms has been established in recent years ${ }^{5}$, but this relationship has not yet been fully elucidated.

Multiple sclerosis is an inflammatory, autoimmune, demyelinating, and degenerative central nervous system (CNS) disease, whose geographic and ethnic distribution is characterized by a higher prevalence in northern hemisphere countries, particularly in populations of Caucasian origin ${ }^{6}$.

The predominantly temperate climate in the northern hemisphere with long periods of low solar radiation and the relatively high prevalence of hypovitaminosis $\mathrm{D}$ observed in population studies ${ }^{7}$ have led to the hypothesis that this deficiency may explain the geographical distribution of MS. Moreover, it has been suggested that adequate serum levels of vitamin D could help reduce the risk of developing $\mathrm{MS}^{8,9}$.

Even though the etiology of MS has not yet been fully elucidated, there is evidence that genetic ${ }^{10,11}$ and environmen$\mathrm{tal}^{12}$ factors interact to cause the disease. Among the main environmental factors studied, those more likely associated with MS include certain viruses ${ }^{13}$, smoking ${ }^{14}$, and hypovitaminosis $\mathrm{D}^{15,16}$. The latter is particularly important in the northern hemisphere, where the seasonal variation and subsequent reduction in ultraviolet-B radiation in winter may lead to a higher prevalence of hypovitaminosis D. Some conditions represent risk of hypovitaminosis $\mathrm{D}$ in the general population such as long stay indoors, use of sunscreen, and skin pigmentation ${ }^{17,18}$. Motor limitations associated with later stages of MS may contribute to the occurrence of hypovitaminosis D in this group of patients ${ }^{19}$.

Unlike northern hemisphere countries, solar radiation in Brazil is believed to be plentiful in all seasons and regions to prevent hypovitaminosis D. Thus, the amount of sunlight one is exposed in Brazil should be enough to avoid hypovitaminosis D in healthy individuals when exposed to sunlight even for short periods. Nevertheless, no studies have compared serum vitamin D levels among Brazilian regions, whereas few studies have analyzed serum vitamin D levels in a selected risk group ${ }^{20}$.

Preliminary experimental studies have demonstrated an immunomodulatory role of vitamin D on human immune cells in vitro ${ }^{21,22}$ and in an experimental animal model $(\mathrm{EAE})^{23,24}$. An in vitro study with peripheral blood cells of patients on vitamin $\mathrm{D}$ therapy showed that serum levels above $40 \mathrm{ng} / \mathrm{ml}$ may exert modulatory action on immune cells ${ }^{20}$. Additional studies are underway to better understand this immunomodulatory effect on autoimmune diseases.

This review aimed to determine whether there is evidence to recommend the use of vitamin $\mathrm{D}$ as monotherapy or as adjunct therapy in patients with MS. We searched PUBMED, EMBASE, COCHRANNE, and LILACS databases for studies published until September $9^{\text {th }}, 2013$, using the keywords "multiple sclerosis", "vitamin D", and "clinical trial". Randomized controlled clinical trials with vitamin D in patients with MS were included in the analysis.

\section{RANDOMIZED AND CONTROLLED CLINICAL TRIALS WITH VITAMIN D IN THE TREATMENT OF MS}

To evaluate the therapeutic response of vitamin D in MS patients, we selected double-blind, randomized, controlled clinical trials from the literature ${ }^{25,26-28}$. These studies are still scarce and most were not designed to evaluate therapeutic response to vitamin D. Next, we discuss the most relevant studies.

A clinical study conducted in Finland ${ }^{25}$ in 66 patients with relapsing-remitting multiple sclerosis (RRMS) compared a group with 34 patients using 20,000 IU/week of vitamin D and interferon beta-1b (IFN $\beta$-1b) to another group with 32 patients using IFN $\beta$-1b only. In that study, primary outcomes included tolerability and safety aspects, and number of new lesions and gadolinium enhancing lesions on MRI scans. Secondary outcomes included clinical parameters such as annual relapse rate and changes in the Expanded Disability Scale Score (EDSS), in addition to other imaging parameters. The authors observed that the treated group showed fewer new T2 lesions, but there were no significant differences in clinical parameters between the two groups after 12 months. However, there was a significant reduction in the number of gadolinium enhancing lesions in the vitamin D group.

Another study, conducted in Norway ${ }^{26}$, compared bone mineral density, relapse frequency, disease progression, and motor function measures between 35 patients with MS using 20,000 IU of cholecalciferol per week associated with 500 
$\mathrm{mg} /$ day of calcium and a control group of 33 patients with MS using $500 \mathrm{mg} /$ day of calcium only for two years ${ }^{26}$. Patients in both groups had been previously using immunomodulatory drugs (interferon beta or glatiramer acetate) for a similar period of time. No differences in annual relapse rate and changes in functional capacity measured by EDSS were observed between the two groups, even though vitamin D levels ranged from $24.72 \mathrm{ng} / \mathrm{ml}$ in the placebo group to $49.26 \mathrm{ng} / \mathrm{ml}$ in the vitamin D group. The study was not powered to address clinical outcomes ${ }^{12}$.

A phase II study developed in $\operatorname{Iran}^{27}$ compared 25 patients with RRMS receiving the active form of vitamin D (calcitri$\mathrm{ol}$ ) at a dose of $0.25 \mu \mathrm{g} /$ day with patients receiving placebo ${ }^{27}$. Both groups used conventional immunomodulators. There was no difference in the EDSS between the calcitriol and placebo groups after 12 months followup ${ }^{13}$. It should be noted in that study the small sample size and inclusion criterion of serum 25-hydroxyvitamin D level $>40 \mathrm{ng} / \mathrm{ml}$.

A randomized study in Australia ${ }^{28}$ compared 11 patients with RRMS treated with vitamin D2 in a dose of 6,000 IU twice daily in addition to a daily low-dose (1,000 IU) with 12 patients receiving the $1,000 \mathrm{IU} /$ day dose only ${ }^{28}$. The neuraxial index of inflammatory activity on MRI was compared between the high-dose and low-dose groups. No significant differences between the groups were detected.

A meta-analysis of the studies cited above detected no difference in the number of relapses between the groups $^{29}$. The number of new lesions and gadolinium enhancing lesions were compared to serum vitamin D levels in other two studies and the findings were conflicting ${ }^{26,30}$. Limitations of the studies include different dosages and forms of vitamin $\mathrm{D}$ administered.

In contrast to epidemiological and experimental studies, randomized trials on the use of vitamin D in MS showed no significant differences in the parameters of disease activity - relapse rate, EDSS progression, and new or gadolinium enhancing lesions on MRI - between the group receiving vitamin D and groups receiving placebo or a smaller dose of vitamin D. These differences and other contradictions indicate the need to conduct double-blind, randomized, controlled trials in large groups of patients, considering the differences between clinical, neuroimaging, biological, and immunological variables, and powered to accurately estimate the therapeutic efficacy and possible side effects of vitamin D in MS.

\section{VITAMIN D AND OTHER ISSUES}

\section{Normal range}

The Institute of Medicine (IOM) and the American Society for Endocrinology advocate different levels of vitamin D to maintain bone health: $\geq 20 \mathrm{ng} / \mathrm{ml}$ and $\geq 30 \mathrm{ng} / \mathrm{ml}$, respectively ${ }^{3,4}$. There is no consensus on whether bone cells and immune cells require different levels of vitamin D. In addition to the lack of consensus on the normal range values for vitamin $D$, the toxic serum concentration and the concentration leading up to this condition are also controversial. In adults, doses greater than or equal to 10,000 IU/day are associated with hypercalcemia ${ }^{31,32}$.

High performance liquid chromatography (HPLC) followed by mass spectrometry is considered the gold standard for analysis of serum 25-OH vitamin D levels. However, the technique is laborious, expensive, and is not available in most Brazilian laboratories. Other methods such as chemiluminescence, enzyme immunoassay, and radioimmunoassay are also used. Thus, variability in results can occur depending on the assay used ${ }^{33}$. In Brazil, there is no efficient inter-laboratory validation system, which can also result in great variability in results. Moreover, certain medications such as anticonvulsants and corticosteroids may have a role in reducing serum levels of vitamin D.

\section{SAFETY PROFILE}

The safety profile of different serum vitamin D levels has been evaluated in an open, randomized study conducted in Canada ${ }^{31}$. In that study, a group of 25 patients with MS used escalating cholecalciferol (vitamin D3) doses up to 40,000 IU/day, whereas a second group of 24 patients used $4,000 \mathrm{IU} /$ day. Patients in both groups used immunomodulators (interferon beta and glatiramer acetate) in combination with cholecalciferol. The maximum 40,000 IU/day dose was used for up to six months, followed by 10,000 IU/day for three months and gradual suspension over three months. Both groups received calcium (1,200 mg/day) throughout the trial, and serum calcium was determined. Serum 25-hydroxivitamin D (25-OH-vitamin D) reached a maximum mean above $250 \mathrm{nmol} / \mathrm{l}(100 \mathrm{ng} / \mathrm{ml})$ during the 40,000 IU/day dosing period. No hypercalcemia was detected during the 10,000 IU/day dosing period, even with serum levels $\geq 100 \mathrm{ng} / \mathrm{ml}$, suggesting that that dose is safe (Class level II evidence). In addition, neither serum calcium nor parathormone urinary levels were altered, even when serum concentrations were higher. Further studies are needed to confirm these findings.

\section{VITAMIN D - SIDE EFFECTS}

Clinical picture of vitamin D intoxication may include signs and symptoms originating in different systems: nausea and vomiting, anorexia, abdominal pain, constipation; polydipsia, polyuria, dehydration, nephrolithiasis, nephrocalcinosis, nephrogenic diabetes insipidus, chronic interstitial nephritis, acute and chronic renal failure; hypotonia, 
paresthesia, confusion, seizures, apathy, coma; arrhythmia, bradycardia, hypertension, cardiomyopathy; muscle weakness, calcification, osteoporosis; and conjunctival calcification $^{34-36}$. Hypercalcemia is the most important side effect, and when observed in the laboratory is suggestive of intoxication ${ }^{37}$.

During use of vitamin D, in addition to serum calcium, urinary calcium should be assayed periodically. Serum concentration of parathyroid hormone (PTH) should also be determined and must not exceed the lower reference values of normality indicative of suppression, which is a non-recommended condition ${ }^{35}$.

\section{FINAL CONSIDERATIONS}

Considering the body of information presented here, the $\mathrm{DCNI} / \mathrm{ABN}$ defines the consensus that:

1. It is recommended to dose vitamin $\mathrm{D}$ in patients with clinically isolated syndrome and MS, regardless of the stage of disease, particularly those making frequent use of corticosteroids or anticonvulsivants.

2. Peripheral blood levels of vitamin D lower than $30 \mathrm{ng} / \mathrm{ml}$ should be corrected in patients with MS, at any stage, or in patients with demyelinating isolated syndrome (grade D recommendation).

3. Peripheral blood levels of vitamin D higher than $100 \mathrm{ng} / \mathrm{ml}$ should be avoided until new guidelines are established (grade D recommendation).

4. There is no scientific evidence up to the production of this consensus for the use of vitamin $D$ as monotherapy for MS in clinical practice. Therefore, currently, vitamin D monotherapy for MS is considered experimental. For its use in clinical trials, these must be approved by the Human Research Ethics Committee, regulated by the National Commission for Ethics in Research (CONEP), approved by the Regional Medical Board, and informed consent should be provided by patients.

5. According to data from in vitro studies with peripheral blood cells of patients using vitamin D, serum levels above $40 \mathrm{ng} / \mathrm{ml}$ are likely to cause modulating action on immune cells ${ }^{17}$. Based on that evidence, vitamin D supplementation at doses that maintain serum levels of patients between $40 \mathrm{ng} / \mathrm{ml}$ and $100 \mathrm{ng} / \mathrm{ml}$ may be recommended, as these are safe levels (grade D recommendation).

6. Considering the individual differences in replacement needs and serum levels of vitamin D, that a study in healthy subjects showed that 5,000 IU/day of vitamin D for 15 weeks increased serum levels up to 60ng/ $\mathrm{ml}$, and that doses up to $10,000 \mathrm{IU} /$ day were considered safe, we recommend individualized doses until reaching serum levels between $40 \mathrm{ng} / \mathrm{ml}$ and $100 \mathrm{ng} / \mathrm{ml}$ (grade D recommendation).

7. Considering that low vitamin D serum levels in patients with isolated demyelinating syndrome could affect the relative risk of conversion to $\mathrm{MS}^{16}$, we recommend the analysis of serum vitamin $\mathrm{D}$ levels in those patients and that a correction is made whenever necessary (grade $\mathrm{D}$ recommendation).

8. Because vitamin D3 is a secosteroid hormone, its use should be escalated. Moreover, monitoring serum 25-hydroxivitamin D would be extremely important before increasing dosage to determine whether supplementation is actually effective (grade $\mathrm{D}$ recommendation).

\section{Acknowledgments}

We thank the contributors who performed critical review of the manuscript: Amilton Antunes Barreira, Danilo Lima Varela, Denis B. Bichuetti, Felipe von Glehn, Eduardo Antônio Donadi, Gutemberg Augusto Cruz dos Santos, Marcos Papais-Alvarenga, Maria Fernanda Mendes, Maria Cecilia Vecino, Maria Lúcia Vellutini, Paulo Pereira Christo, Thiago Faria Junqueira, Soniza Vieira Alvez Leon, and Yara Dadalti Fragoso (Fragoso, YD). We also thank the invaluable expert assistance of Paulo S. Moraes Júnior in using Microsoft Lync for support in the online meeting.

This manuscript was reviewed by a professional science editor and by a native English-speaking copy editor to improve readability.

\section{References}

1. Grant WB, Holick MF. Benefits and requirements of vitamin D for optimal health: a review. Altern Med Rev 2005;10:94-111.

2. Bikle DD. Vitamin $D$ regulation of immune function. Vitam Horm 2011;86:1-21.

3. HolickMF, Binkley NC, Bischoff-Ferrari HA, et al. Evaluation, treatment, and prevention of vitamin D deficiency: an Endocrine Society clinical practice guideline.J Clin Endocrinol Metabl 2011;96:1911-1930.

4. Rosen CJ, Abrams SA, Aloia JF, et al. IOM committee members respond to Endocrine Society vitamin D guideline. J Clin Endocrinol Metab 2012;97:1146-1152.

5. Holick MF. Vitamin D: important for prevention of osteoporosis, cardiovascular heart disease, type 1 diabetes, autoimmune diseases, and some cancers. South Med J 2005;98:1024-1027.
6

Kurtzke J. A reassessment of the distribution of multiple sclerosis. Acta Neurol Scand 1975;51:137-157.

7. Hossein-nezhad A, Holick MF. Vitamin D for health: a global perspective. Mayo Clin Proc 2013;88:720-755.

8. Goldberg P, Fleming MC, Picard EH. Multiple sclerosis: decreased relapse rate through dietary supplementation with calcium, magnesium and vitamin D. Med Hypotheses 1986;21:193-200.

9. Martinelli V, Dalla Costa G, Colombo B, et al. Vitamin D levels and risk of multiple sclerosis in patients with clinically isolated syndromes. Mult Scler 2013, Epub Ahead of Print

10. Ebers GC, Bulman DE, Sadovnick AD, et al. A populationbased study of multiple sclerosis in twins. $N$ Engl $J$ Med 1986;315:1638-1642. 
11. Sawcer S, Hellenthal G, Pirinen M, et al. Genetic risk and a primary role for cell-mediated immune mechanisms in multiple sclerosis. Nature 2011;476:214-219.

12. Cantorna MT, Mahon BD. Mounting evidence for vitamin D as an environmental factor affecting autoimmune disease prevalence. Exp Biol Med (Maywood) 2004;229:1136-1142.

13. Lucas RM, Ponsonby AL, Dear K, et al. Current and past EpsteinBarr virus infection in risk of initial CNS demyelination. Neurology 2011;77:371-379.

14. Hedström AK, Sundqvist E, Bäärnhielm M, et al. Smoking and two human leukocyte antigen genes interact to increase the risk for multiple sclerosis. Brain 2011;134:653-664.

15. Ascherio A, Munger K. Epidemiology of multiple sclerosis: from risk factors to prevention. Semin Neurol 2008;28:17-28.

16. Munger KL, Levin LI, Hollis BW, Howard NS, Ascherio A. Serum 25-hydroxyvitamin $D$ levels and risk of multiple sclerosis. JAMA 2006;296:2832-2838.

17. Maeda SS, Saraiva GL, Kunii IS, et al. Factors affecting vitamin D status in different populations in the city of Sao Paulo, Brazil: the Sao PAulo vitamin D Evaluation Study (SPADES). BMC Endocr Disord 2013;13:14.

18. Libon F, Cavalier E, Nikkels AF. Skin color is relevant to vitamin D synthesis. Dermatology 2013;227:250-254.

19. Smolders J, Menheere P, Kessels A, Damoiseaux J, Hupperts R. Association of vitamin $D$ metabolite levels with relapse rate and disability in multiple sclerosis. Mult Scler 2008;14:1220-1224.

20. Arantes HP, Kulak CA, Fernandes CE, et al. Erratum to: correlation between 25-hydroxyvitamin D levels and latitude in Brazilian postmenopausal women: from the Arzoxifene Generations Trial. Osteoporos Int 2013;24:2899-2900.

21. Kimball S, Vieth R, Dosch HM, et al. Cholecalciferol plus calcium suppresses abnormal PBMC reactivity in patients with multiple sclerosis. J Clin Endocrinol Metab 2011;96:2826-2834.

22. Allen AC, Kelly S, Basdeo SA, et al. A pilot study of the immunological effects of high-dose vitamin D in healthy volunteers. Mult Scler 2012;18:1797-1800.

23. Farias AS, Spagnol GS, Bordeaux-Rego P, et al. Vitamin D3 induces IDO(+) tolerogenic DCs and enhances Treg, reducing the severity of EAE. CNS Neurosci Ther 2013;19:269-277.

24. Correale J, Ysrraelit MC, Gaitán MI. Vitamin D-mediated immune regulation in multiple sclerosis. J Neurol Sci 2011;311:23-31.
25. Soilu-Hänninen M, Aivo J, Lindström BM, et al. A randomised, double blind, placebo controlled trial with vitamin D3 as an add on treatment to interferon $\beta-1 \mathrm{~b}$ in patients with multiple sclerosis. J Neurol Neurosurg Psychiatry 2012;83:565-571.

26. Kampman MT, Steffensen LH, Mellgren SI, Jørgensen L. Effect of vitamin D3 supplementation on relapses, disease progression, and measures of function in persons with multiple sclerosis: exploratory outcomes from a double-blind randomised controlled trial. Mult Sclerg 2012;18:1144-1151.

27. Shaygannejad V, Janghorbani M, Ashtari F, Dehghan H. Effects of adjunct low-dose vitamin d on relapsing-remitting multiple sclerosis progression: preliminary findings of a randomized placebo-controlled trial. Mult Scler Int 2012;2012:452-541.

28. Stein MS, Liu Y, Gray OM, et al. A randomized trial of high-dose vitamin D2 in relapsing-remitting multiple sclerosis. Neurology 2011;77:1611-1618.

29. James E, Dobson R, Kuhle J, Baker D, Giovannoni G, Ramagopalan SV. The effect of vitamin D-related interventions on multiple sclerosis relapses: a meta-analysis. Mult Scler 2013;19:1571-1579.

30. Mowry EM, Waubant E, McCulloch CE, et al. Vitamin D status predicts new brain magnetic resonance imaging activity in multiple sclerosis. Ann Neurol 2012;72:234-240.

31. Gallo S, Comeau K, Vanstone C, et al. Effect of different dosages of oral vitamin D supplementation on vitamin D status in healthy, breastfed infants: a randomized trial. JAMA 2013;309:1785-1792.

32. Burton JM, Kimball S, Vieth R, et al. A phase I/II dose-escalation trial of vitamin D3 and calcium in multiple sclerosis. Neurology 2010;74:1852-1859.

33. Roth HJ, Schmidt-Gayk H, Weber H, Niederau C. Accuracy and clinical implications of seven 25-hydroxyvitamin D methods compared with liquid chromatography-tandem mass spectrometry as a reference. Ann Clin Biochem 2008;45:153-159.

34. Koul PA, Ahmad SH, Ahmad F, Jan RA, Shah SU, Khan UH. Vitamin d toxicity in adults: a case series from an area with endemic hypovitaminosis d. Oman Med J 2011;26:201-204.

35. Zittermann A, Prokop S, Gummert JF, Börgermann J. Safety issues of vitamin D supplementation. Anticancer Agents Med Chem 2013;13:4-10.

36. Ashizawa N, Arakawa S, Koide Y, Toda G, Seto S, Yano K. Hypercalcemia due to vitamin $D$ intoxication with clinical features mimicking acute myocardial infarction. Intern Med 2003;42:340-344.

37. Bell DA, Crooke MJ, Hay N, Glendenning P. Prolonged vitamin D intoxication: presentation, pathogenesis and progress. Intern Med J 2013;43:1148-1150. 